\title{
Indigenous peoples' food systems for health: finding interventions that work
}

\author{
Harriet Kuhnlein*, Bill Erasmus, Hilary Creed-Kanashiro, Lois Englberger, Chinwe Okeke, \\ Nancy Turner, Lindsay Allen and Lalita Bhattacharjee on behalf of the whole groupt \\ Centre for Indigenous Peoples' Nutrition and Environment (CINE), McGill University, Macdonald Campus, 21111 \\ Lakeshore Road, Ste. Anne de Bellevue, Quebec, Canada, H9X 3V9
}

Submitted 31 January 2006: Accepted 13 February 2006

\begin{abstract}
This is a short report of a 'safari' held in conjunction with the International Congress of Nutrition in September 2005, in Futululu, St. Lucia, South Africa. Participants were several members of the International Union of Nutritional Sciences Task Force on Indigenous Peoples' Food Systems and Nutrition, other interested scientists and members of the Kwa Zulu indigenous community. The paper describes the rationale for and contributions towards understanding what might be successful interventions that would resonate among indigenous communities in many areas of the world. A summary of possible evaluation strategies of such interventions is also given.
\end{abstract}

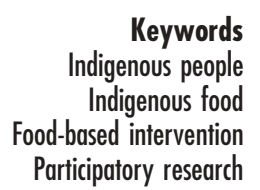

The health of indigenous peoples globally is intricately related to their ecosystems and the complexities of their social and economic circumstances. All over the world, indigenous peoples often face extreme poverty with all its multiple dimensions and implications, that make them among the most marginalised and vulnerable human populations. And yet they control a wealth of knowledge of their ecosystems, including knowledge of their native foods, that merges with health and healing knowledge embedded in local culture and practice. This knowledge is a resource of truly global proportions to be used for their benefit. It also is of immense potential benefit to more economically privileged populations such as those in highincome countries that have lost touch with natural sources of food and their value and function in maintaining health and protecting against disease. Indigenous peoples have much to teach the industrialised world.

This paper describes how indigenous peoples and their academic partners in 12 rural regions (Fig. 1) think about protecting, using, developing and sustaining local food system knowledge for improving well-being and health in their communities, and thus also protecting their culture. It is a report of a meeting of partners held in the St. Lucia Futululu Centre as a Pre-Congress Safari of the International Congress of Nutrition in September 2005. The meeting was an activity of the Task Force on Indigenous Peoples' Food Systems and Nutrition of the International Union of Nutritional Sciences. The list of authors (Appendix) reflects the breadth of indigenous community and academic partners who contributed to the content.

tA full list of authors is given in the Appendix.
In general, the nutrition and health of indigenous communities is among the worst of all communities, in any country ${ }^{1}$. This situation is not helped by a rather oversimple view, among the public health authorities responsible for the health of indigenous peoples, that their nutrition-related problems are largely confined to stunting and micronutrient malnutrition in middle- and low-income countries, and to obesity, diabetes and its complications, and dental caries and tooth loss, in highincome countries. These problems do exist and are important, but are only one part of the story. Also, indigenous communities do have their own resources and knowledge that should be nurtured.

Our project proposes that the long-evolved food systems of indigenous peoples amount to a treasure of knowledge that is typically overlooked and undervalued; which has potential benefits for the well-being and health not only of indigenous peoples themselves, but also industrialised and other populations. This perception is now becoming more widely shared.

Thus, a principle suggested for the new nutrition science', an initiative of the International Union of Nutritional Sciences, is: 'All nutritional theory, policy and practice should take into account, the diet-related evolutionary pressures that shaped the biological evolution of the hominid line and, eventually, Homo sapiens'. Another suggested principle, of direct relevance to longevolved indigenous food systems, is: 'Food and nutrition practices consistently followed in different cultures in history are probably valid - though not necessarily for the reasons given. They do not require proof to be accepted; they require disproof to be rejected ${ }^{2}$. 


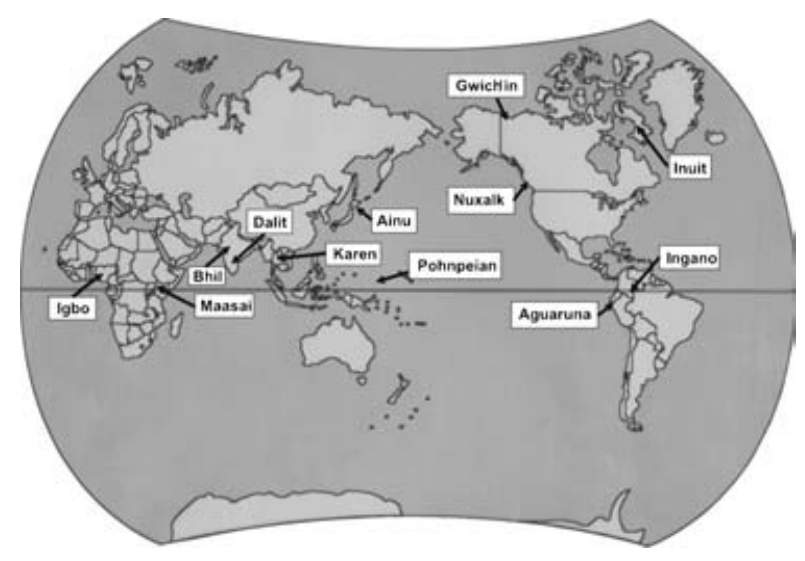

Fig. 1 Location of indigenous peoples for case studies

\section{Focus on the problems}

The evidence base of the health status of indigenous peoples worldwide needs to be strengthened. Many middle- and low-income nations do not yet accrue health data by ethnic group. That said, data compiled for children in the Americas clearly show infant mortality 20 to 500\% higher than country averages, and stunting 20-360\% higher $^{3}$. In North America, Australia and New Zealand, obesity, diabetes and associated chronic diseases affect indigenous populations in higher proportions than the non-indigenous ${ }^{4-7}$.

Reasons for these increased prevalences include changes in food, nutrition and physical activity levels and a general shift away from traditional ways of life. There is also evidence of accentuated genetic vulnerability.

Thus, in Canada since the 1940s, there has been an increase in permanent settlements for indigenous peoples, leading to a dependence on purchased 'market' and 'store' foods and a decrease in the importance of foods derived from hunting, fishing, gathering and traditional agriculture. Diets have become more energy-dense and higher in fats, sugars and salt contained, for example, in soft drinks and snack foods ${ }^{8,9}$.

Environmental, social and economic conditions profoundly impact the health of indigenous peoples. While life expectancy has improved for Canadian indigenous peoples in recent years, virtually all health status measures for every health condition are still worse for First Nations, Inuit and Métis than the overall Canadian population, with poorer conditions for education, employment and average income being key determinants ${ }^{10}$. Over $80 \%$ of Canadian First Nations and Inuit respondents to a health survey agreed that attention to and practice of traditional ways of life would help promote community well-being ${ }^{11}$, and that disconnection from health services must be remedied ${ }^{12}$.

These well-attested concerns occur in the midst of global alarm about increasing obesity and chronic disease which affect rich and poor alike because of globalisation of food systems ${ }^{13}$, and which can be triggered by foetal impairment in areas of poor nutrition ${ }^{14}$. As the poorest of the poor in most nations, indigenous peoples are especially vulnerable to effects of the combination of foetal and infant undernutrition followed by energy-dense infant and childhood foods.

To develop strategies for prevention and management of conditions and diseases such as stunting, micronutrient malnutrition and diabetes and its correlates in indigenous populations, food security ${ }^{15}$ and health care must be improved. Indigenous peoples are themselves well aware of their risks for food insecurity. At an international meeting held in Atitlán, Guatemala in 2002, difficulties and frustrations with protecting their food environments and livelihoods were eloquently described by indigenous leaders, who called for global action to promote food sovereignty for indigenous peoples, and to protect traditional lands and food resources ${ }^{16,17}$.

\section{Indigenous communities contribute solutions}

Our work addresses the local food systems and the wellbeing and health of indigenous peoples in 12 deliberately diverse settings, where undernutrition and/or overnutrition are of concern. It is concerned to find ways for community empowerment, development, and self-sufficiency to improve knowledge and understanding of good food, so that it becomes more available and accessible and used in ways that improve health.

The objectives universally embraced by community leaders in the group include the use of indigenous food resources to encourage, educate and build capacity for increasing dietary quality of youth, adults and elders; and working towards making local cultural food resources sources of community pride, pleasure and responsibility, thereby ensuring local determination and sustainability of intervention effort.

In areas where obesity and diabetes are common, increasing physical activity and reducing the purchase and consumption of poor-quality, imported and refined 'market' and 'store' food (refined foods oils, sugared beverages and other energy-dense processed foods, including those high in fat/sugar/salt content) are targets, as are improving knowledge of, access to and use of local cultural food.

The overall ultimate goal of the Task Force and the project is to provide evidence to show that indigenous peoples' local and traditional food systems are central to public health improvement, and require policies at local, national and international levels for protection of food environments to ensure food security and quality ${ }^{18,19}$

There is impetus for increasing knowledge of, access to and use of local food resources by indigenous peoples. This comes from the United Nations Human Rights Commis$\operatorname{sion}^{20}$, the Permanent Forum on Indigenous Issues ${ }^{21}$ and the International Decade of the World's Indigenous Peoples and its renewal, and other sources ${ }^{22}$. Further, the United Nations' Millennium Development Goals urge 
attention to many principles affecting indigenous peoples (reduce hunger, sustainable development, child and maternal mortality, empowerment of women, access to nutritious food, etc. $)^{23}$; and the UNEP Convention on Biological Diversity targets indigenous and local peoples' food systems for environmental protection ${ }^{24}$.

Such programmes address indigenous peoples' food security issues, but do not include any fully developed plans amounting to a blueprint on how to go about the basic, formative research and community-level education and development required for addressing these problems. Our Task Force and the meeting have accepted this challenge. This is to improve health and nutrition using a multidisciplinary, holistic approach grounded in collaboration with community leaders and women, who are the custodians and users of local food, and their academic partners. This paper is the result of extensive consultation among the 12 case studies of diverse cultures and ecosystems for a wide variety of community ideas and reflections on intervention activities and project evaluation. It presents needed perspective on how to go about improving nutritional health of indigenous peoples within local cultures and ecosystems.

This project evolved from the desperation expressed by indigenous peoples at the loss of food resources that are integral to their evolved cultures and ways of life. This cry, echoed by elders, leaders and youth, is that indigenous peoples can survive as cultures only with rights and access to their land and knowledge and ability to make full use of the food it provides.

Food relates to social needs and local economy. Indigenous peoples have their own unique perspectives on the relationships between environment and culture, and food, well-being and health, in many dimensions. This knowledge is precious to them. It also has many lessons for industrialised nations and populations.

There is a clear imperative to protect unique food resources and their diversity. There are 300-500 million indigenous peoples in more than 70 countries around the world, representing over 5000 languages and cultures on every continent, and each cultural food system may contain up to 250 species of traditional food alone (among additional bioresources for medicines and life ways). This knowledge base is a treasure worthy of global attention and protection ${ }^{8,25}$.

One way forward is to provide evidence and documentation of successful food-based interventions that have had and are having the effect of improving the well-being and health of indigenous peoples, especially in rural communities where indigenous foods and knowledge of its nature and value are still present, and where protection policies can be effective.

Our work deals with the holistic knowledge of and beliefs about food, well-being and health held by indigenous peoples. It recognises that food touches on the physical, psychological, social and spiritual dimensions of all age and gender groups in community life. Therefore, it is essential to build community support and action for sustainability and for self-determination that 'makes sense to us', and can build wellness and dignity to local ways of knowing what a valuable and healthy life is. The project strives to identify commonalities, differences, priorities and challenges in a diversity of communities wanting to increase knowledge of, access to and use of their local food. In this way it should be possible for individual communities to improve their well-being and health, and also make a contribution to the improved wellbeing and health not only of other indigenous communities, but also of industrialised populations.

\section{Indigenous community and academic partnership}

Each of the case study communities, containing 500-3000 members, have partnered with an academic in-country leader to contribute to two project phases. Phase 1 has been completed by all to date, and has resulted in documentation of the local food system using modifications to a methodology published on the website of the Centre for Indigenous Peoples' Nutrition and Environment ${ }^{26}$. Results show a staggering range of local food species and cultural styles and values for their use. (In addition to the 12 groups contributing here, the Phase 1 methods also had experience and input from the Mogh in Bangladesh, Miao in Sechuan Province of China, Aetas of Philippines, Hausas of Niger, the Zulu of South Africa, and 44 communities of Arctic Indigenous Peoples in Canada ${ }^{27-29}$ ).

As the current 12 case studies were completing Phase 1, plans took shape for the intervention phase (Phase 2). Ideas for interventions acceptable and appealing to communities developed first at the community level and were transmitted to the group in on-line meetings with academic partners and face-to-face meetings of the 12 indigenous community leaders and academic partners in Bellagio, Italy (2004), and during the workshop/safari in St. Lucia's Futululu Centre, South Africa (2005). To date, Phase 2 has been completed for two case studies and is in process for the others. Each indigenous community area plans interventions and measures based in local circumstances - giving an overall richness of knowledge of relevant activities that have appeal in indigenous areas. Obviously, with diversity in health conditions (e.g. micronutrient malnutrition vs. obesity/diabetes), not all activities and evaluation measures are appropriate for all case studies.

Case study partners collectively agreed that the best way to evaluate these kinds of interventions containing multiple activities is comparison of pre- and postintervention measures. In most cases, control groups were not available with identical culture and ecological circumstances. Funding constraints also preclude working with reasonably small community collectives. This method does not permit evaluation of particular activities, but instead evaluates the entire community effort towards 
Table 1 Indigenous peoples' food system intervention ideas

Traditional food harvest of wild plant/animal resources

Stimulate more community hunting/gathering/fishing along with conservation training

Gain more access to land/water needed to improve harvests

Prioritise elders and women/youth to receive products harvested

Teach food harvesting and preparation to youth

Stimulate community freezers, smokehouses and other traditiona buildings for food storage and sharing

Use political leverage and agreements to ensure land access

\section{Agriculture activities}

Stimulate home or community gardens and local food production, including livestock and seafood

Distribute traditional plantings: trees, shrubs, seedlings, seeds

Train farmers about high-nutrient crops

Work with local extension agents for better harvests, emphasising nutrient-rich local food and varieties, and improving soil fertility

Combine traditional and modern agriculture methods

Develop fish farms and mollusc farms, or other unusual food farms

Develop gardens of medicinal plants

Encourage formation of groups to work together on planting emphasise crop diversity, improving soil fertility, crop

management and size/volume of harvest

Work on increasing land access

Improve water access and quality, if needed

\section{Activities in community schools}

Target curriculum and learning in schools around local food and nutrition

Involve the children to take messages home

Develop traditional food materials for schools and community

Initiate learning on crop cultivars and food variety diversity and their health benefits

Distribute recipe books and traditional food handbooks with food species photos

Hold local food preparation classes

Involve school authorities to ensure sustainability

Suggest and prepare traditional food snacks

Target vending in schools/communities to reduce high-sugar beverages and sweet/fat snacks

\section{General community projects}

Involve elders and work with culture committees

Emphasise 'the food that makes us feel good health-wise and cultural-wise'

Establish regular community meetings discussing project topics; have refreshments with healthy local food

Develop women's groups as the home food providers for education and other activities

Develop education activities on traditional food and market food

Train all community health workers about traditional food resources

Include activities blending culture-health-nature with Shaman knowledge

Work with individuals - counselling in person or by telephone

Train volunteers to help as 'health brigades'

Prepare posters, calendars, pamphlets, etc. for homes and community centres with photos of local food; include local residents with their favourite food/recipes

Encourage traditional food dishes for celebrations and feasts, giving attention to high-nutrition items

Hold food and/or recipe competitions with food prizes, games

Develop physical activity events for community/schools and emphasise traditional food harvest and events

Stimulate activities involving local food production and harvest

Create drama scenes for public events and media that emphasise community indigenous food issues and conflict scenarios

Hold cooking classes: children, others for healthy eating

Hold food budgeting classes emphasising traditional and healthy market food (best buys for food providing more nutrients at least cost)

Hold nutrition education information sessions
Work with store managers to improve good food availability both traditional and good-quality market food

Conduct tours of stores to highlight good food; improve availability of traditional food

Invite guests for school/community presentations - consider famous/stars/celebrities; include indigenous leader role models

Make resource materials for homes or health workers emphasising local food with print, visual, video, sound

Work with the mass media - radio, television, newspapers - to promote local indigenous foods to raise status of local food and acknowledge those involved

Publicise and hold community health assessments anthropometry, diet, blood pressure, cholesterol, etc. - giving results back to participants with explanations

Organise 'healthy weight and weight loss' competitions; include waist measures

Stimulate physical activity, especially for children; find ways to reduce television watching time

Links with health care, agriculture, education, government, business, NGOs

Engage a local steering committee of leaders to ensure activities lead to positive health outcomes

Involve local and regional health care, education and agriculture workers in several disciplines to be part of activities

Work with prenatal programmes to emphasise healthy traditional food for mothers, infants, toddlers and children; involve the elders

Involve churches when important in community

Establish email network of leaders in all sectors, including local businesses, to share progress with regular messages on health, nutrition and local food

Work with local businesses and NGOs to sell/display project materials (recipe books, posters, foods) promoting local food and health

Meet with local leaders to increase awareness of project, need for their support and potential to extend to other communities

NGO - non-government organisation.

making a difference in health within their priorities. The ideas presented in Tables 1 and 2 are a straight compilation of point-form ideas contributed by case studies during the meeting. Although not an exhaustive list, these ideas are presented as a menu to choose from, that give insights on the breadth of activities mentioned that have appeal to indigenous communities for improving health through food access.

Successful public health work with indigenous communities depends entirely on good process. Techniques for development of community interest and participation in interventions is not the topic of this report, but it is essential for intervention success that the community informs and controls the research, and shapes it to its own priorities ${ }^{30}$.

In each case, consent for the study and the project and its goals was obtained at three levels - from the collective, from each community and from participating individuals $^{31-33}$. Academic and community partners and their steering committees shared information and expertise to derive activities for interventions and evaluation measures that included both mainstream and indigenous forms of action and knowing, and that reflect community values.

In all case studies the interventions are rooted in local ecosystems and are community-driven, with inclusion of capacity building and empowerment, particularly of women, to guide strengthening of local food systems. 
Table 2 Indicators for measuring intervention success in indigenous communities

Knowledge and beliefs
Food knowledge - traditional (including crop varieties) and
market food
Beliefs and knowledge about good local food and links to health
'problems'
Food security - appropriately measured in the local context

Food, diet, general health, and environment

Extent of breast-feeding and types of complementary feeding practices for infants

Dietary diversity with traditional, local food

Dietary frequency of using target food; preferred by season

Percentage of energy from traditional food

Percentage of target nutrients from traditional food

Time spent in traditional food and good food activities

Nutrient adequacy by age/gender

Physical activity - appropriately measured in the local context

Recent morbidity event frequency

Numbers of health-risk individuals

Numbers of the most marginalised individuals

Environment and social indicators; family income

Environment indicators to sustain increased traditional food

School absenteeism: consider whether health or home activity reasons

Process indicators (measures taken and records kept)

Consents from the collective, community and individuals for participation

Each project activity, number of participants and general success of activity (use a standardised form)

Overall number of activities

Percentage of population involved in activities

Increases in numbers of participants in activities

Significant events: what, when, why, how

Numbers distributed: flyers, seedlings, etc.

Numbers of media events (what kind) - radio, television, other

Extent of community leaders involved

Formation and conduct of lobbying groups

Involvement of new links to government, health, businesses, non-government organisations, societies

Land area used for traditional food

Number and/or quantity of foods (and crop varieties) produced

Food preservation activities

Reports of: environmental improvement

Food availability to community: what kind, seasonality, quantity

Number of traditional food ceremonies

Number of people trained in aspects of traditional food and good-quality market food

Networks developed for sharing food: who, what

Availability of local food for sharing or sale at schools and shops

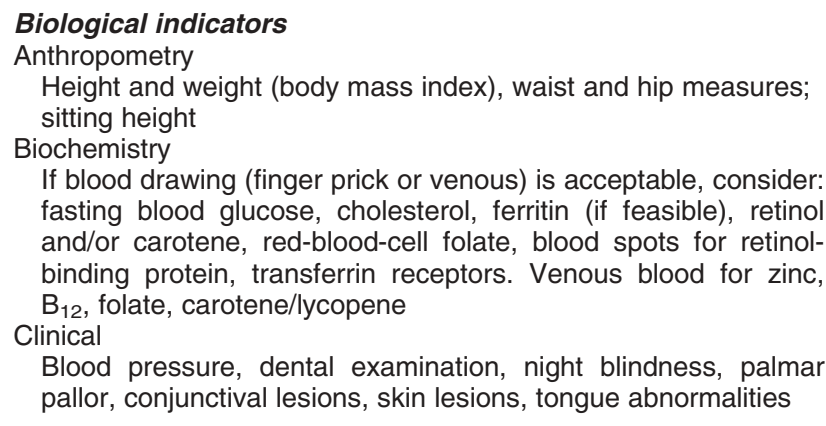

\section{Ideas for interventions and their evaluation}

Table 1 gives the ideas generated by participants in point form on how to improve food and nutrition circumstances in indigenous communities. It includes ideas about improving access to traditional food as well as (for higherincome regions) stimulating purchase of better-quality market food, and avoiding the pitfalls of 'food colonisation'.

Considering the whole, it presents ideas that will likely have appeal and feasibility to indigenous peoples everywhere, although it cannot be considered a complete listing. Categories of activities are loosely grouped according to food system type, with separate categories for hunting/ gathering/fishing and agriculture-based food systems.

Table 2 presents evaluation measure ideas that evolved first from the academic partners and were explained, discussed and expanded with community leaders and health representatives. As stated earlier, the intent of the programme is to have similar pre- and post-intervention measurements, with the focus here for areas with micronutrient malnutrition and/or concerns for obesity, diabetes and related chronic diseases. In some cases consent was not given for human biological samples, because of cultural values and perceptions.

Consideration must be given to biological indicators if there is a high prevalence of malaria (cannot use ferritin) or HIV/AIDS (special blood handling requirements); in all cases consultation with public health officers is recommended before sampling. Dietary and food measures and process indicators are universally acceptable by the participants, if interview times are reasonably short. Both qualitative and quantitative data are seen as important to capture models of success in health evaluations of indigenous communities.

We offer this information for all who endeavour to improve food, nutrition, well-being and health in rural indigenous communities by emphasising food systems from the local culture and ecosystem.

Efforts to support and build local control of food resources are at the heart of the New Nutrition Science project, an initiative of the International Union of Nutritional Sciences ${ }^{34}$.

\section{Acknowledgements}

Funding is acknowledged from the Canadian Institutes of Health Research, Institute of Aboriginal Peoples' Health and Institute of Population and Public Health, the International Development Research Centre, and The Rockefeller Foundation. We also thank Frances Davidson, Biplab Nandi, T Longvah, Siri Damman, Martina Schmid, Prasit Wangpakapattannawong, Verónica Vázquez-Garcia, Lizzy Shumba, Audrey Maretzki and Sakorn Dhanamitta for contributions to discussions. We are especially grateful to Geoffrey Cannon for editorial comments.

There is no conflict of interest.

\section{References}

1 Stephens C, Nettleton C, Porter J, Willis R, Clark S, Indigenous peoples' health - why are they behind everyone, everywhere? Lancet 2005; 366: 10-3. 
2 Leitzmann C, Cannon G. Dimensions, domains and principles of the new nutrition science. Public Health Nutrition 2005; 8: 787-94.

3 Damman S. Nutritional vulnerability in indigenous children of the Americas - a human rights issue. In: Eversole R, McNeish J, Cindamore A, eds. Exclusion and Vulnerability in Indigenous Peoples. Crop Poverty Series. London: Zed Books, 2005: Chapter 5.

4 Ross K, Taylor J. Improving life expectancy and health status: a comparison of indigenous Australians and New Zealand Maori. A joint special issue of the Journal of Population Research and the New Zealand Population Review 2002: 219-38.

5 Young TK, Reading J, Elias B, O'Neil JD. Type 2 diabetes mellitus in Canada's First Nations: status of an epidemic in progress. Canadian Medical Association Journal 2000; 163 561-6.

6 Smith P, Smith A, Richard M. Diets in transition. Huntergatherer to station diet and station diet to the self-select store diet. Human Ecology 1999; 27: 115-35.

7 Lee AJ, Bailey APV, Yarmirr D, O'Dea K, Mathews JD. Survival tucker: improved diet and health indicators in an Aboriginal community. Australian Journal of Public Health 1994; 18: $277-85$.

8 Kuhnlein HV, Receveur O. Dietary change and traditional food systems of indigenous peoples. Annual Review of Nutrition 1996; 16: 417-42.

9 Ritenbaugh C, Szathmary EJE, Goodby CS, Feldman C. Dietary acculturation among the Dogrib Indians of the Canadian Northwest Territories. Ecology of Food and Nutrition 1996; 35: 81-94.

10 Canadian Population Health Initiative. Improving the Health of Canadians. Ottawa: Canadian Institute for Health Information, 2004.

11 Svenson K, Lafontaine C, The First Nations and Inuit Regional Health Survey National Steering Committee. The search for wellness: National First Nation and Inuit Health Surveys; National Core Content Paper. Ottawa: First Nation and Inuit Regional Health Survey Project - National Steering Committee and Health Canada Medical Services Branch. National Aboriginal Information and Research Conference, 29 March 1998.

12 O'Neal J, Leader A, Elias B, Sanderson D, members of the Manitoba Regional Health Survey Steering Committee. Manitoba Regional Health Survey: a preliminary report of selected results. Ottawa: First Nation and Inuit Regional Health Survey Project - National Steering Committee and Health Canada Medical Services Branch. National Aboriginal Information and Research Conference, 29 March 1998.

13 Popkin BM, Gordon-Larsen P. The nutrition transition: worldwide obesity dynamics and their determinants. International Journal of Obesity and Related Metabolic Disorders 2004; 28: S2-9.

14 Barker DJP. The developmental origins of adult disease. Journal of the American College of Nutrition 2004; 23: 588S-95S.

15 Eldis. FAO Mandate in the World Food Summit Plan of Action (1996) [online]. Available at http://www.eldis.org/ static/DOC6759.htm. Accessed 7 October 2005.

16 International Indian Treaty Council. http://www. treatycouncil.org [homepage]. Accessed 7 October 2005.

17 Kuhnlein HV, Erasmus B, Kalafatic C. Indigenous peoples' consultation on the right to food: Declaration of Atitlán, Guatemala. SCN News 2002; 24: 74-50. Excerpts available at http://www.cine.mcgill.ca/atitlan.htm. Accessed 7 October 2005.

18 Kuhnlein HV, Johns TA, Spigelski DL, Erasmus B. Indigenous peoples' food systems and health. Prepared for the $32 n d$
Session of the Standing Committee on Nutrition of the United Nations System, Brasilia, 14-18 March 2005.

19 Englberger L, Marks GC, Fitzgerald MH. Factors to consider in Micronesian food-based interventions: a case study of preventing vitamin A deficiency. Public Health Nutrition 2004; 7: 423-31.

20 Eide WB. From food security to the right of food. In: Eide WB, Kracht U, eds. Food and Human Rights in Development. Volume I. Legal and Institutional Dimensions and Selected Topics. Antwerp: Intersentia, 2005; 67-97.

21 UN Permanent Forum on Indigenous Issues. http://www.un. org/esa/socdev/unpfii [homepage]. Accessed 7 October 2005.

22 Office of the United Nations High Commissioner for Human Rights. International Decade of the World's Indigenous People (1995-2004) [online]. Available at http://www. ohchr.org/english/issues/indigenous/decade.htm. Accessed 7 October 2005

23 UN Millennium Development Goals. What are the Millennium Development Goals? [online]. Available at http://www. un.org/millenniumgoals. Accessed 7 October 2005.

24 Convention on Biological Diversity. The Convention on Biological Diversity [online]. Available at http://www. biodiv.org/convention/default.shtml. Accessed 7 October 2005.

25 Cobo JM. Quote from United Nations Permanent Forum on Indigenous Issues [online]. Available at http://www.un.org/ esa/socdev/unpfii/pfii/dpi2309.htm. Accessed 7 October 2005.

26 Kuhnlein HV, Smitasiri S, Yesudas S, Bhattacharjee L, Dan L, Ahmed S. Documenting Traditional Food Systems of Indigenous Peoples: International Case Studies. Guidelines for Procedures. Ste-Anne-de-Bellevue: Centre for Indigenous Peoples' Nutrition and Environment, 2004. Also available at http://www.cine.mcgill.ca/documents/manual.pdf. Accessed 7 October 2005.

27 Kuhnlein HV, Receveur O, Soueida R, Egeland GM. Arctic indigenous peoples experience the nutrition transition with changing dietary patterns and obesity. Journal of Nutrition 2004; 124: 1447-53

28 Centre for Indigenous Peoples' Nutrition and Environment. Traditional Food Systems Research with Indigenous Peoples in Asia [online]. Available at http://www.cine.mcgill.ca/IA1. htm. Accessed 7 October 2005.

29 Kuhnlein HV, Pelto GH, eds. Culture, Environment, and Food to Prevent Vitamin A Deficiency. Boston, MA/Ottawa: International Nutrition Foundation for Developing Countries/International Development Research Centre, 1997.

30 Ten Fingers K. Rejecting, revitalizing, and reclaiming. First Nations work to set the direction of research and policy development. Canadian Journal of Public Health 2005; 96: S60-3.

31 Erasmus B, Kuhnlein HV. Participatory research with indigenous peoples: procedures developed with the Centre for Indigenous Peoples' Nutrition and Environment. In: Vorster HH, Blaaum R, Dhansay MA, Kuzwayo PMN, Moeng TL, Wentzel-Viljoen E, eds. Proceedings of the 18th International Congress of Nutrition, Durban, South Africa, 19-23 September 2005 [CD-ROM]. Basel: Karger, 2005.

32 World Health Organization and Centre for Indigenous Peoples' Nutrition and Environment. Indigenous Peoples and Participatory Health Research. Planning and Management/Preparing Research Agreements [online], 2003. Available at http:// www.who.int/ethics/indigenous_peoples/en/index1.html. Accessed 7 October 2005.

33 Government of Canada. Tri-Council Policy Statement: Ethical Conduct for Research Involving Humans. Section 6 - Research Involving Aboriginal People [online], 1998 (with 2000, 2002 updates). Available at http://www.pre.ethics.gc. 
ca/english/policystatement/section6.cfm. Accessed 7 October 2005.

34 Leitzmann C, Cannon G, eds. The New Nutrition Science project [special issue]. Public Health Nutrition 2005; 8 667-804.

\section{Appendix - Full list of authors}

Harriet Kuhnlein, Bill Erasmus, Hilary Creed-Kanashiro, Irma Tuesta, Lois Englberger, Adelino Lorens, Kiped
Albert, Chinwe Okeke, Nkechi Ene-Obong, Igwe PE Eze, Camilo Correal, Natividad Mutumbajoy Janasoy, Hazel Nerysoo, Rose Hans, Nancy Turner, Gopa Kothari, Lalita Bhattacharjee, Motiram Chaudhary, Gail Harrison, Lindsay Allen, Salome Yesudas, PV Satheesh, Dina Spigelski, Joseph Ole Simel, Timothy Johns, Grace Egeland, Jonah Kilabuk, Laurie Chan, Masami IwasakiGoodman, Miwako Kaizawa, Suttilak Smitasiri and Sompop Sungklachalatarn. 